\title{
The computational simulation of coupled heat and moisture transport as a tool for predicting the degradation of sedimentary porous rocks in historical masonry
}

\author{
V. Kočí, Z. Pavlík, J. Fořt \& R. Černý \\ Department of Materials Engineering and Chemistry, \\ Faculty of Civil Engineering, Czech Technical University in Prague, \\ Czech Republic
}

\begin{abstract}
A method for the prediction of the degradation problems of sedimentary porous rocks in historical buildings, which has not been frequently used until now, is presented. It consists of a combination of computational and experimental approaches. In the experimental part, durability of the rocks is determined in terms of their frost resistance. In the computational part, a diffusion-type model is used for the description of coupled heat and moisture transport aimed at the identification of the number of frost cycles in a real structure. The prediction of moisture and temperature fields in the envelope parts of historical buildings over a sufficiently long time makes it possible to not only make a reliable estimate of the service life of the applied rocks on the basis of a sufficient amount of input parameters, but also to create a design of the time schedule of possible repairs. As a practical example, several historical walls composed of different types of sandstone are chosen. The influence of the different material parameters of the sandstones on their service life is analyzed, depending on the environmental conditions in a given locality. Conclusions are drawn on the most advantageous type of sandstone for the particular locations with respect to service life.

Keywords: sandstone, building envelope, finite element method, dynamic climatic conditions, freeze/thaw resistance, computational analysis.
\end{abstract}




\section{Introduction}

For many centuries, porous sedimentary rocks have been popular structural and artistic materials in many European countries. Sandstone, as one of them, has been used since prehistoric times and still continues to be used. Because of its relative softness making it easy to carve, it was very popular particularly from ancient times. It has been widely used around the world in the construction of temples, cathedrals, homes and other buildings.

Sandstones, as well as most other sedimentary rocks, are characterized by a more or less porous structure and often by poor or moderate mechanical properties. Thus, some of them are resistant to weathering, some of them are not. For example, Collyhurst sandstone, widely used in North West England, has been found less resistant, necessitating repair and replacement in older buildings.

The durability of sandstone is an important issue which affects their service life in a structure. Therefore, the prediction of their performance in historical masonry is an important task, which can provide the supervisory authorities with valuable information on their course of degradation.

In the past, the selection of sandstone for construction purposes depended especially on the location of sandstone deposits because of the limited transport possibilities. Historical sandstone buildings were then widely built in Central Europe (Poland, Czech Republic), West Europe (Germany, France, England, Scotland, Ireland), or South Europe (Italy), where substantial sandstone deposits were located. At present, the transport possibilities are significantly more extensive. Therefore, sandstones from long distance (even from overseas) can be used.

In this paper, we analyze the effects of different dynamic climatic conditions on the degradation of several types of sandstone. As the main degradation process we focused on weathering, especially the effects of freeze/thaw cycles. As boundary conditions we used Test Reference Year (TRY) hourly data for London, Mannheim, Nantes, Prague and Warsaw, which represent the countries where sandstone has a strong tradition.

\section{Analyzed sandstones and their parameters}

Three different types of sandstone commonly available in the Czech Republic were analyzed. They originated from the quarries Mšené-lázně (denoted as SM in what fallows), Božanov (SB) and Hořice (SH). They were formed by suboval quartz clasts, tourmaline, epidote, muscovite and zircone [1].

Material properties (basic physical properties, water transport properties, water vapor transport properties, sorption isotherms and thermal properties) of the studied sandstones were measured by Vejmelková et al. [1] according to the methodology described by Černý [2].

Freeze/thaw resistance was calculated as the ratio of the compressive strength of the frost loaded material, and the reference material without freezing/thawing cycles exposure. One single freezing/thawing cycle required 6 hours freezing at $-15^{\circ} \mathrm{C}$ and 6 hours thawing in $20^{\circ} \mathrm{C}$ warm water [3]. The total number of applied 
cycles was $14,28,42,56$ and 70 . Compressive strength as a comparative parameter of freeze/thaw resistance was measured in a standard way by a hydraulic testing device on cubic samples of side $100 \mathrm{~mm}$.

While SM sandstone was disrupted already after 14 freeze/thaw cycles, frost resistance coefficients $k$ of SB and SH sandstones after 70 cycles were equal to $0.77(\mathrm{SB})$ and $0.79(\mathrm{SH})$. Therefore, because of having $k>0.75$ they could be considered as frost resistant.

The material parameters applied in the computational model as input data are summarized in Tables 1 and 2 and Figures 1 and 2. The following symbols are used: $\rho$ - bulk density $\left[\mathrm{kg} / \mathrm{m}^{3}\right], \psi-$ porosity [\%], $c-$ specific heat capacity $[\mathrm{J} / \mathrm{kgK}], \mu-$ water vapor diffusion resistance factor $[-], \lambda-$ thermal conductivity $[\mathrm{W} / \mathrm{mK}]$.

Table 1: Material parameters of sandstones.

\begin{tabular}{|l|c|c|c|}
\hline Parameter & SM & SB & SH \\
\hline$\rho\left[\mathrm{kg} / \mathrm{m}^{3}\right]$ & 1807 & 2154 & 2004 \\
\hline$\psi[\%]$ & 31.0 & 16.1 & 21.6 \\
\hline$c[\mathrm{~J} /(\mathrm{kg} \mathrm{K})]$ & $780-1204$ & $675-847$ & $808-1101$ \\
\hline$\mu[-]$ & $5.49-6.98$ & $7.18-13.38$ & $5.77-11.59$ \\
\hline$\lambda[\mathrm{W} / \mathrm{mK}]$ & $1.367-3.595$ & $3.420-6.235$ & $2.535-5.150$ \\
\hline
\end{tabular}

Table 2: Freeze/thaw resistance of sandstones.

\begin{tabular}{|l|c|c|c|}
\hline Parameter & SM & SB & SH \\
\hline $\begin{array}{l}\text { Number of freeze thaw } \\
\text { cycles [-] }\end{array}$ & $<14$ & $>70$ & $>70$ \\
\hline$k$ (after 70 cycles) [-] & - & 0.77 & 0.79 \\
\hline
\end{tabular}

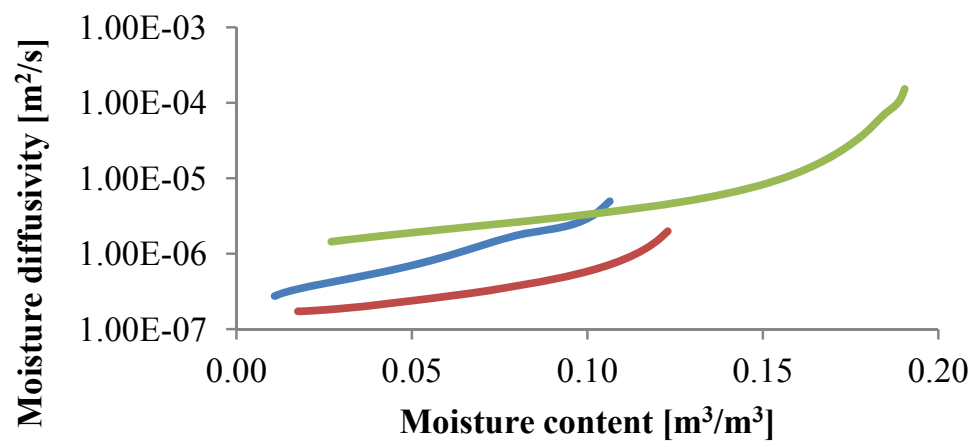

$\longrightarrow \mathrm{SB} \longrightarrow \mathrm{SH} \longrightarrow \mathrm{SM}$

Figure 1: Moisture diffusivity vs. moisture content function of sandstones. 


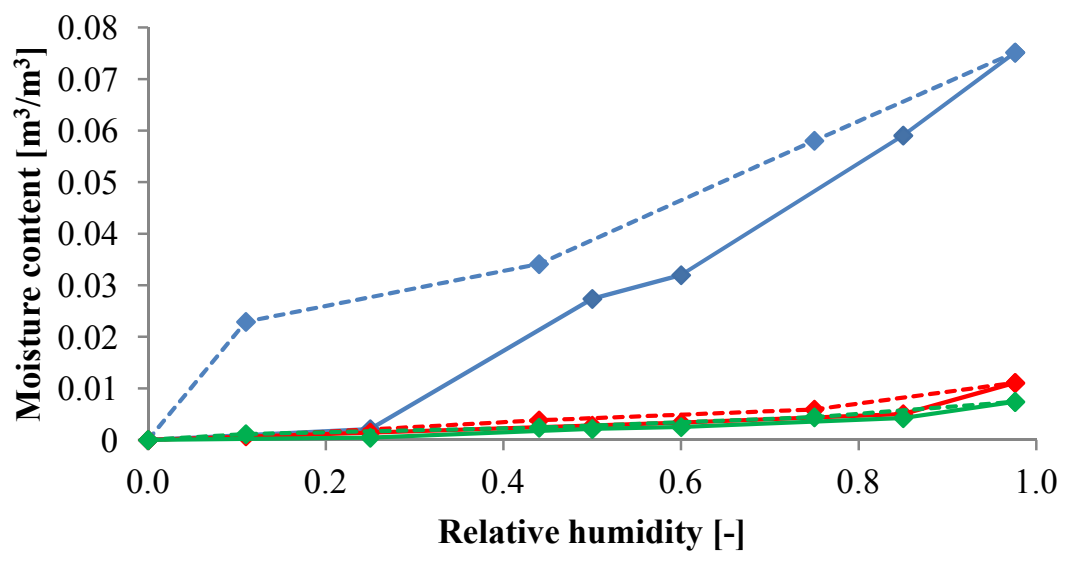

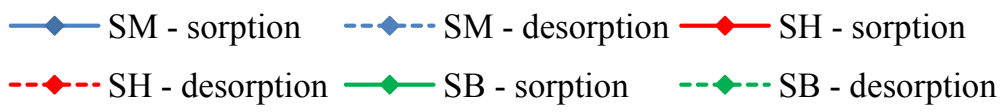

Figure 2: Sorption isotherms of sandstones.

\section{Computational simulation}

The computational analysis was performed using the computer code HEMOT [4], which is based on the general finite element package SIFEL [5]. The basic parameters of the analysis, i.e., the mathematical model, the scheme of the construction detail, initial and boundary conditions and the time specification of the simulation are described in what follows.

\subsection{Mathematical model}

Künzel's mathematical model of heat and moisture transport [6] was used in the simulations which can be formulated as

$$
\begin{gathered}
\frac{d \rho_{v}}{d \varphi} \frac{\partial \varphi}{\partial t}=\operatorname{div}\left[D_{\varphi} \operatorname{grad} \varphi+\delta_{p} \operatorname{grad}\left(\varphi p_{s}\right)\right] \\
\frac{d H}{d T} \frac{\partial T}{\partial t}=\operatorname{div}(\lambda \operatorname{grad} T)+L_{v} \operatorname{div}\left[\delta_{p} \operatorname{grad}\left(\varphi p_{s}\right)\right]
\end{gathered}
$$

where $\rho_{v}$ is the partial density of moisture, $\varphi$ relative humidity, $\delta_{p}$ permeability of water vapor, $p_{s}$ partial pressure of saturated water vapor, $H$ enthalpy density, $L_{v}$ heat of evaporation of water, $\lambda$ thermal conductivity and $T$ temperature, 


$$
D_{\varphi}=D_{w} \frac{d \rho_{v}}{d \varphi}
$$

is liquid moisture diffusivity coefficient, $D_{w}$ capillary transport coefficient.

\subsection{Scheme of the construction detail}

As the reference building envelope for simulations performed in this paper, the external wall made of three different sandstones was chosen. The wall was not provided with any plaster or thermal insulation material. The thickness of the wall was set to $500 \mathrm{~mm}$. The scheme of analyzed building envelope is depicted in Figure 3.

\subsection{Boundary conditions and time interval of simulation}

Dynamic climatic data in the form of Test Reference Year (TRY) for London (UK), Mannheim (Germany), Nantes (France), Prague (Czech Republic) and Warsaw (Poland) were applied on the exterior side of building envelope [7]. TRY contains long-term average hourly values of temperature, relative humidity, wind velocity and direction, rainfalls and several kinds of sun radiation.

On the interior side of building envelope, constant values of relative humidity $55 \%$ and temperature $21^{\circ} \mathrm{C}$ were used. These data are prescribed in ČSN 73 0540-2:2011 Thermal protection of buildings - Part 2: Requirements [8]. The simulation took 5 years, in order to reach a dynamic steady state. All the presented results are related to the fifth year of simulation. Scheme of the applied boundary conditions is shown in Figure 3.

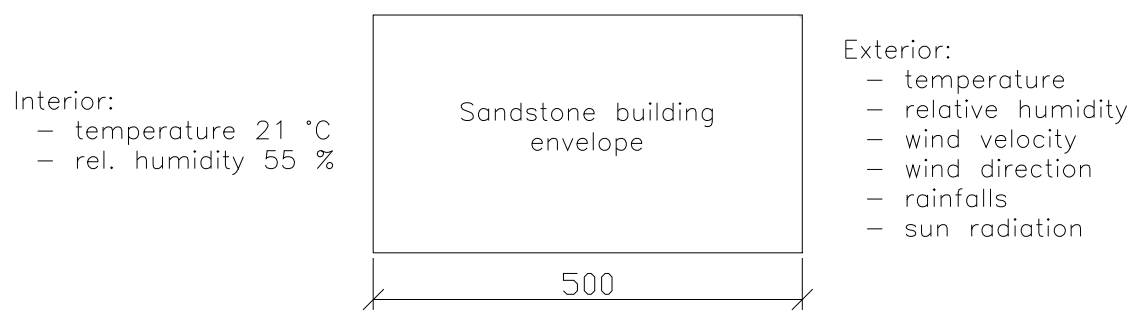

Figure 3: Scheme of the analyzed building envelope and the applied boundary conditions.

\subsection{Local climates}

London has a temperate oceanic climate, similar to much of southern Britain. Winters are generally chilly to cold with frost usually occurring in the suburbs on average twice a week from November to March. Winter temperatures seldom fall below $-4^{\circ} \mathrm{C}$ or rise above $14^{\circ} \mathrm{C}$. Summers are generally warm and sometimes hot, 
the heat being boosted by the urban heat island effect making the centre of London at times $5^{\circ} \mathrm{C}$ warmer than the suburbs and outskirts. London's average July high is $24^{\circ} \mathrm{C}$.

Mannheim with oceanic climate is located in Germany's warmest region, the "Rhine shift". In summer, temperatures sometimes rise up to $35^{\circ} \mathrm{C}$ and higher. The daily lows during that time are also very high (around $25^{\circ} \mathrm{C}$ ). In a comparison to other regions of Germany, Mannheim has a higher humidity in summer which causes a higher heat index. Snow is rare, even in the cold months. Precipitation occurs mostly during afternoon thunderstorms during the warmer period (average days of thunderstorms in a year is 40-50). Climate in this area has mild differences between highs and lows, and there is adequate rainfall year round.

Nantes has a Western European oceanic climate, with frequent rainfalls all year round and cool temperatures. Fall and winter days are generally rainy with cold temperatures often falling below zero and moderate snowfalls in the coldest months. Spring and summer days are sunny to cloudy with mild temperatures and occasional summer hot spells especially during the month of July.

Prague has a borderline oceanic climate. The winters are relatively cold with very little amount of sunshine. Snow cover is common between mid-November to late March but is usually not too heavy. Summers usually bring fine sunny days with highs being around 25 degrees. Nights can be quite cool even in summer, though. Precipitation in Prague is rather low as the shadow of the Ore Mountains and the Czech Central Highlands takes effect. The driest season is usually winter while the summers can bring quite heavy rain especially in form of violent storms and showers.

Warsaw's climate is humid continental with cold winters and warm summers. The average temperature is $-3.0^{\circ} \mathrm{C}$ in January and $19.3^{\circ} \mathrm{C}$ in July. Temperatures may often reach $30^{\circ} \mathrm{C}$ in the summer. Average winter temperatures drops between $-3.1^{\circ} \mathrm{C}$ (in December) and $-6.1^{\circ} \mathrm{C}$ (in January).

\section{Results and discussions}

The service life of the studied building envelopes was estimated according to the resistance against weathering effects; freeze/thaw cycles in particular. Freeze/thaw cycles are characterized by the water/ice phase conversions which are accompanied by volumetric changes. This effect presents the essence of the disrupting mechanism. In this paper, only such freeze/thaw cycle applied on a porous material was considered as a possible cause of damage if two basic conditions were met at the same time. First, the moisture content had to reach the overhygroscopic (liquid) range. Second, the temperature had to drop below zero for at least two hours which represented a typical time necessary for water/ice phase change to take effect. All the freeze/thaw cycles were monitored in a characteristic point $2 \mathrm{~mm}$ under the external surface.

Under London's climate all the sandstones gave almost identical results. There were 6 freeze/thaw cycles per a reference year in SB and SM sandstone and 5 freeze/thaw cycles in SH sandstone. Comparing these results with 
experimental data of freeze/thaw resistance, SH sandstone could be considered as the most resistant one under this climate, while SM sandstone could show signs of damage already after 2 years because of its poor freeze/thaw resistance parameters. Moisture content and temperature vs. time function of SH sandstone is shown in Figure 4. It is obvious that the main cause of the appearance of freeze/thaw cycles was an increased moisture content, rather than a low temperature.

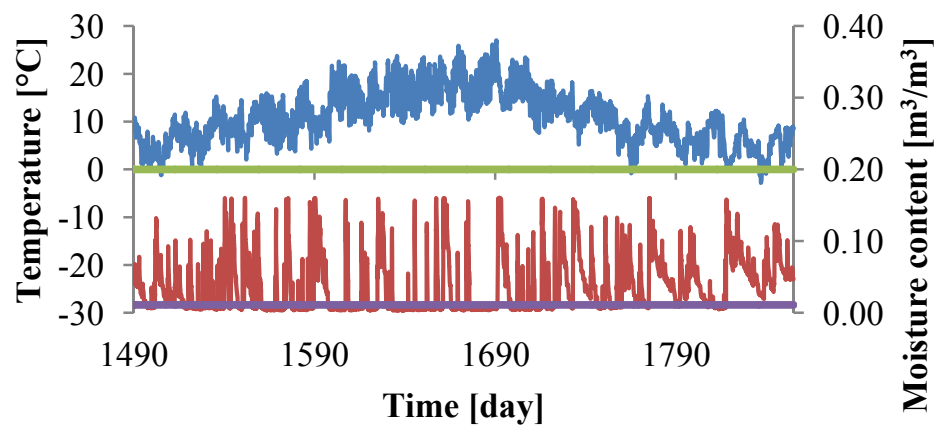

- Temperature

Temperature $0^{\circ} \mathrm{C}$

Moisture content

Hygroscopic moisture content

Figure 4: Temperature and moisture content vs. time function, $\mathrm{SH}$, London.

Because Mannheim's climate is very similar to London's, also the results were similar, in a qualitative sense. Anyway, slight differences could be observed: while temperature of air was almost identical, different relative humidity of air for these two locations, in a combination with different water and water vapor transport and accumulation parameters of analyzed sandstones, resulted in certain differences in the hygric behavior which led to different numbers of freeze/thaw cycles appearing during a reference year. SM sandstone evinced only three freeze/thaw cycles per a reference year, but in case of SB and $\mathrm{SH}$ this number was higher. Seven freeze/thaw cycles were counted in $\mathrm{SH}$ sandstone and five cycles appeared in SB. However, combining computational results with the results of freeze/thaw resistance, as the best solution was the application of SB sandstone, which functionality without any signs of damage was supposed to be at least 14 years. Moisture content and temperature vs. time function of SM sandstone is captured in Figure 5. 


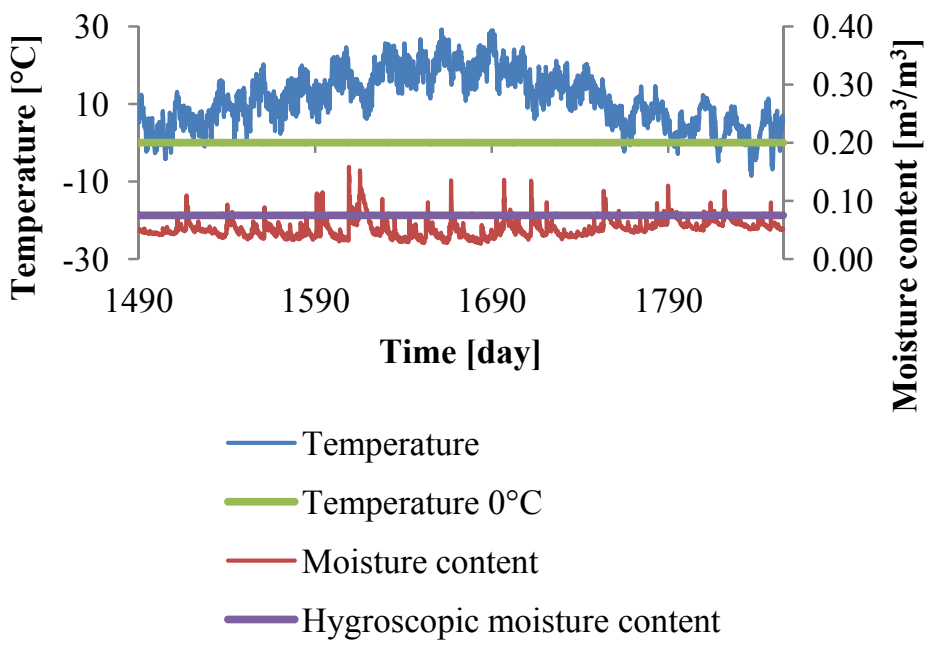

Figure 5: Temperature and moisture content vs. time function, SM, Mannheim.

Nantes climatic conditions were the most considerable to sandstone constructions among all the investigated locations. In comparison with London, the temperature was even higher while the relative humidity of air during reference year was lower. Average yearly temperature in Nantes was $1^{\circ} \mathrm{C}$ higher than temperature in London. Consequently, a very long service life could be predicted to SB sandstone, because there were only two freeze/thaw cycles counted during a reference year. The worst results ( 9 freeze/thaw cycles) were given when SM sandstone was used. It could be summarized that the service life of sandstone structures under climatic conditions of Nantes was very variable, depending on the type of sandstone. While the first signs of damage on SM sandstone could be identified already after two years, SM sandstone could reliable resist more than 35 years. Moisture content and temperature vs. time function of SB sandstone is shown in Figure 6.

Prague's and Warsaw's reference climatic years could be very harsh to the sandstone structures, because especially in winter period temperature very often dropped below zero while relative humidity was often very high. Under these conditions hygric parameters of sandstones played a significant role from the point of view of frost resistance. Materials, such as SB and SH, with relatively low moisture diffusivity (Figure 1) and hygroscopic moisture content (Figure 2) contained liquid moisture during longer time periods, which increased a risk of its subsequent freezing. In a comparison with SB and SH sandstones, SM sandstone had the lowest water vapor diffusion resistance factor (Table 1). This was very important, because it led to the prevention of water vapor accumulation and its subsequent possible condensation. Even if liquid moisture appeared, thanks to the high moisture diffusivity reaching up to $1.0-10^{-4} \mathrm{~m}^{2} / \mathrm{s}$ it could be very quickly transported and spread out. Under Prague's, as well as Warsaw's climatic conditions, SM sandstone showed only one freeze/thaw cycle per a 
reference year. The same could not be stated about SB and SH, because there were identified up to 20 freeze/thaw cycles during a reference year. Moisture content and temperature vs. time function of SM sandstone under Prague's climatic conditions can be seen in Figure 7, the same function of SH under Warsaw's climatic conditions is captured in Figure 8.

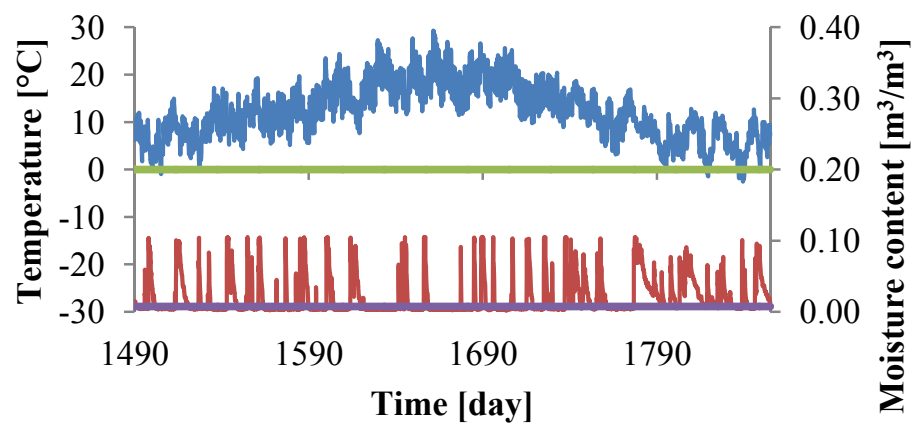

— Temperature

- Temperature $0^{\circ} \mathrm{C}$

- Moisture content

Hygroscopic moisture content

Figure 6: Temperature and moisture content vs. time function, SB, Nantes.

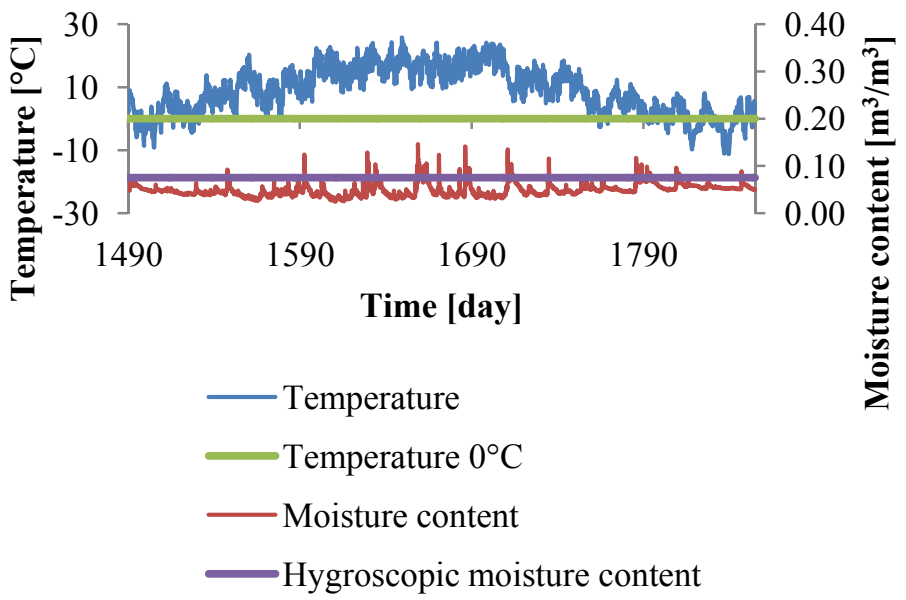

Figure 7: Temperature and moisture content vs. time function, SM, Prague. 


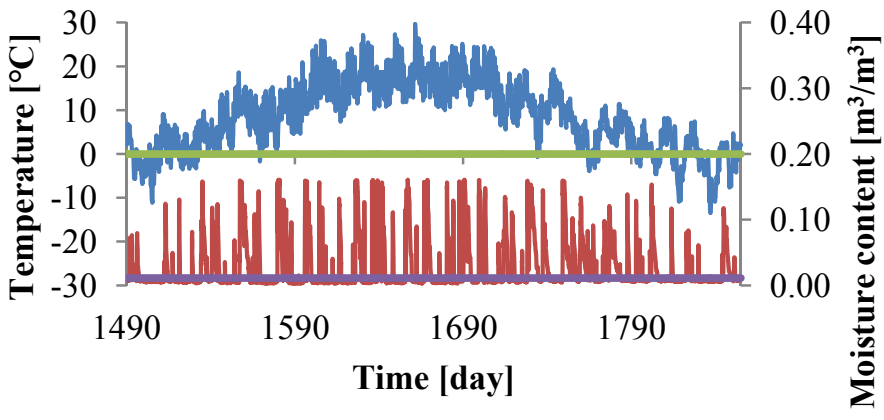

- Temperature

- Temperature $0^{\circ} \mathrm{C}$

- Moisture content

Hygroscopic moisture content

Figure 8: Temperature and moisture content vs. time function, $\mathrm{SH}$, Warsaw.

The numbers of freeze/thaw cycles identified using computational analysis, together with estimated service life, are summarized in Table 3. It should be noted that because unprotected sandstone masonry is exposed to the effects of weather conditions in a significant way, it would be possible to protect it using external plaster in order to increase its service life. However, as results of the previous research showed [9], optimal properties of external plasters have to be found in advance, otherwise the service life can be even decreased. External plaster should contain hydrophobic agents to restrict the liquid water intake and at the same time, it has to be vapor permeable to allow water vapor evaporation as much as possible. Meeting these conditions can lead to an elimination of appearance of freeze/thaw cycles which means, the service life of building envelope would not be limited by its freeze/thaw resistance

Table 3: Results of computational analysis.

\begin{tabular}{|c|c|c|c|c|c|c|}
\hline & \multicolumn{2}{|c|}{ SM } & \multicolumn{2}{|c|}{ SB } & \multicolumn{2}{|c|}{ SH } \\
\hline & 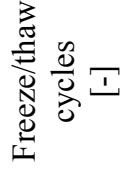 & 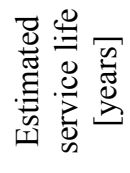 & 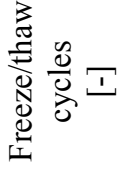 & 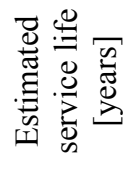 & 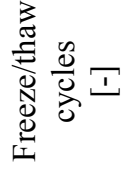 & 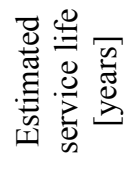 \\
\hline London & 6 & $<2$ & 6 & $>12$ & 5 & $>14$ \\
\hline Mannheim & 3 & $<5$ & 5 & $>14$ & 7 & $>10$ \\
\hline Nantes & 9 & $<2$ & 2 & $>35$ & 4 & $>18$ \\
\hline Prague & 1 & $<14$ & 10 & $>7$ & 15 & $>5$ \\
\hline Warsaw & 1 & $<14$ & 18 & $>4$ & 20 & $>4$ \\
\hline
\end{tabular}




\section{Conclusions}

Computational simulation of the degradation processes taking place in three different types of sandstone used in the historical masonry as a result of the appearance of freeze/thaw cycles was presented in the paper. The moisture and temperature fields obtained using numerical modeling of coupled heat and moisture transport served as a basic tool for estimating the service life of the analyzed sandstones. The results of experimental analysis of freeze/thaw resistance complemented then the computational data and made possible the necessary quantification in terms of the estimated number of years of damagefree service of the particular sandstones under different climatic conditions

The main outcome of the analysis was the finding that sandstone can be very unpredictable building material from the point of view of hygric or thermal performance. As it is a natural sedimentary porous rock, its properties are very variable, depending on the quarry location, time of origin, mineralogical composition, etc. In addition, for obtaining the best results from a point of view of frost resistance, it is not only sufficient to perform experimental measurements of freeze/thaw resistance according to the prescribed standards, because the number of freeze/thaw cycles appearing in sandstone exposed to dynamic climatic conditions can differ in a large extent, depending on the type of sandstone and the climatic load. Apparently, it is important to combine this approach also with the results of numerical simulation of moisture and temperature fields, which can predict the number of freeze/thaw cycles.

Among the three sandstones analyzed in this paper, the application of SM was appropriate under harsh climatic conditions (Prague, Warsaw), where temperature often dropped below zero; it was mainly due to its suitable hygric properties. SB was identified as an optimal type of sandstone for Nantes' and Mannheim's climatic conditions, which are characterized by moderate amount of rainfalls. On the other hand, application of $\mathrm{SH}$ sandstone proved to be the best option in London's climate, which is distinguished by high relative humidity and frequent rainfalls.

\section{Acknowledgement}

This research has been supported by the Czech Science Foundation, under project No 14-17207S.

\section{References}

[1] Vejmelková, E., Keppert, M., Reiterman, P. \& Černý, R., Mechanical, hygric and thermal properties of building stones. Proc. of the $13^{\text {th }}$ Int. Conf. on Studies, Repairs and Maintenance of Heritage Architecture STREMAH 2013, ed. C.A. Brebbia, WIT Press: Southampton, pp. 357-367, 2013.

[2] Černý, R., (ed). Complex System of Methods for Directed Design and Assessment of Functional Properties of Building Materials and Its Application, CTU Prague: Prague, 2013. 
[3] ČSN EN 12371, Natural stone test methods - Determination of frost resistance, Czech Office for Standards, Metrology and Testing: Prague, 2010.

[4] Černý, R., (ed). Complex System of Methods for Directed Design and Assessment of Functional Properties of Building Materials: Assessment and Synthesis of Analytical Data and Construction of the System, CTU Prague: Prague, 2010.

[5] Kruis, J., Koudelka, T. \& Krejčí, T., Efficient computer implementation of coupled hydro-thermo-mechanical analysis. Mathematics and Computers in Simulation, 80, pp. 1578-1588, 2010.

[6] Künzel, H.M. Simultaneous Heat and Moisture Transport in Building Components, Ph. D. Thesis, IRB Verlag: Stuttgart, 1995.

[7] Meteonorm, Version 6.0, software version 6.1.0.20 from April 2010. Meteotest, Switzerland.

[8] ČSN 73 0540-2 Thermal Protection of Buildings - Part 2: Requirements, Czech Office for Standards, Metrology and Testing: Prague, 2011.

[9] Kočí, V., Maděra, J. \& Černý, R., Exterior thermal insulation systems for AAC building envelopes: Computational analysis aimed at increasing service life. Energy and Buildings, 47, pp. 84-90, 2012. 